\title{
The National Map—New Data Delivery Homepage, Advanced Viewer, Lidar Visualization
}

\author{
https://www.usgs.gov/NationalMap/data
}

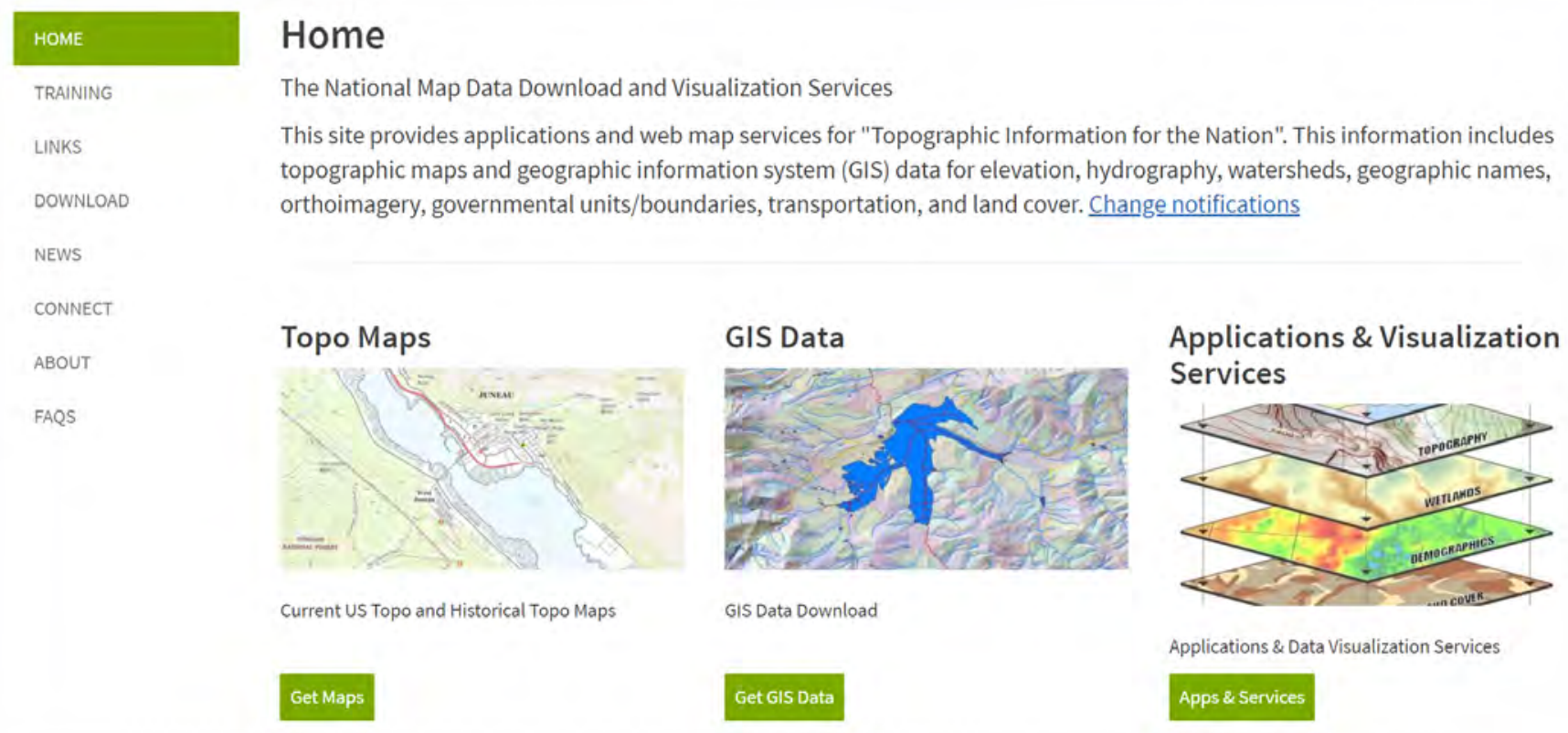

As one of the cornerstones of the U.S. Geological Survey's (USGS) National Geospatial Program, The National Map is a collaborative effort among the USGS and other Federal, State, and local partners to improve and deliver topographic information for the Nation. The National Map is featuring direct links to new and improved GIS data access utilities on a refreshed data delivery homepage at https://www.usgs.gov/NationalMap/data. From the homepage, users can now quickly access topographical map products, GIS data, and the full suite of The National Map's applications and visualization services.

\section{Viewer}

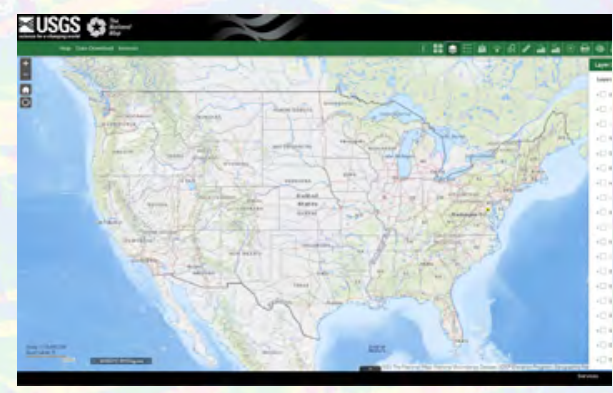

Download Client

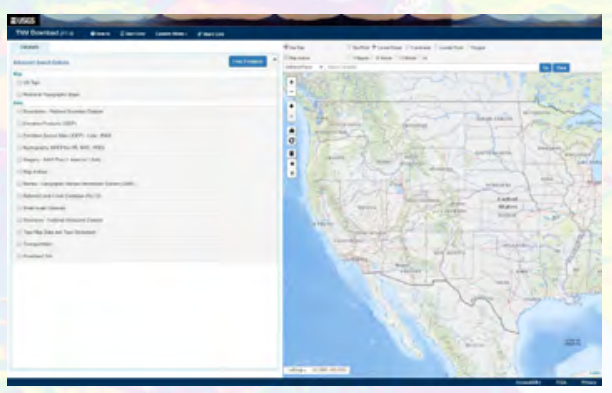

Lidar Explorer

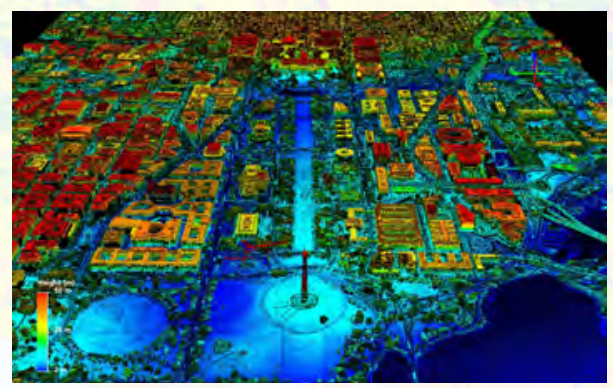

The following is a list of some of the capabilities available through the National Map applications.

- Create and export maps using The National Map's online data. Even import your own data into the viewer for display and map creation.

- Search or browse The National Map's extensive data catalog and select from several methods for downloading.

- Find and explore lidar point clouds in 3D through the Lidar Explorer.

- Access current and historical topo maps available in GeoPDF and GeoTIFF formats. 


\section{Live Data for your Applications:}

Five web base maps and more than 40 thematic data layers are available as overlays.

\section{Base Maps}

Five cached high-performance base maps are available to 1:9000 scale - Cloud hosted for reliability, Topo and Imagery Topo for rich cartographic rendering, and Shaded Only and Imagery Only for backdrops.

\section{Overlay Map Services}

\section{Sample Overlay Services-Available in Viewer and Other Applications}

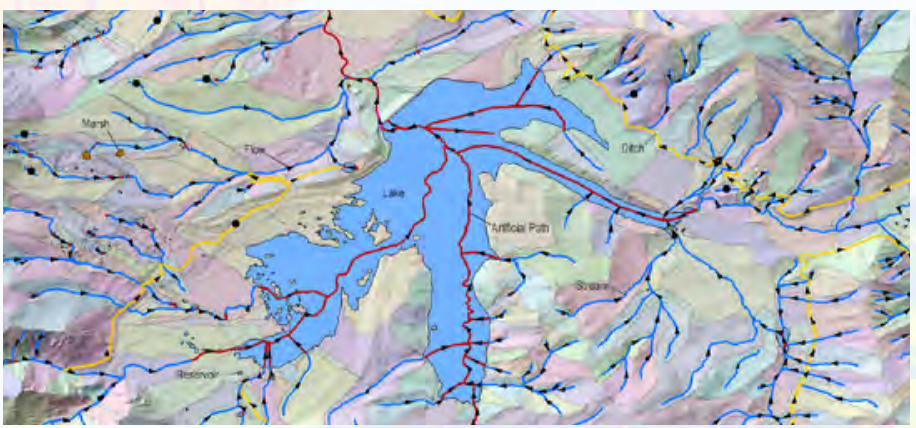

National Hydrography Dataset (NHD) Services-Dynamic large scale NHD overlay with flow direction and other significant hydrographic features.

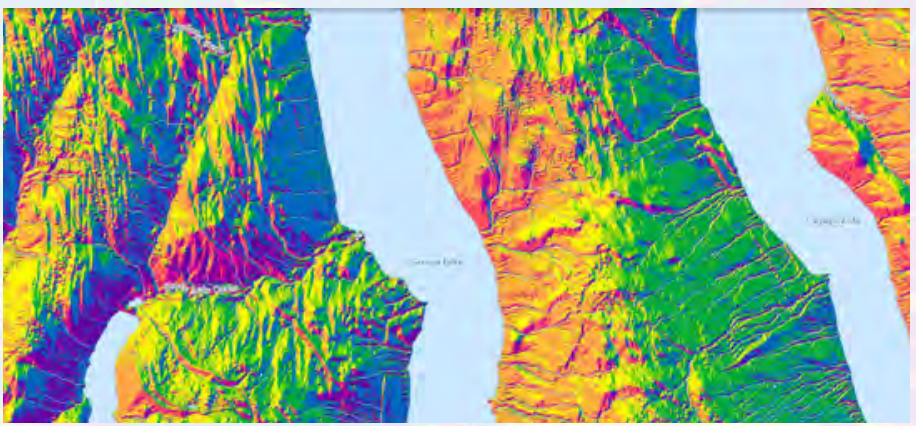

New 3D Elevation Program (3DEP) Elevation Layers-Slope, Hillshade, Stretched Hillshade, Aspect Map, Contours, and more.
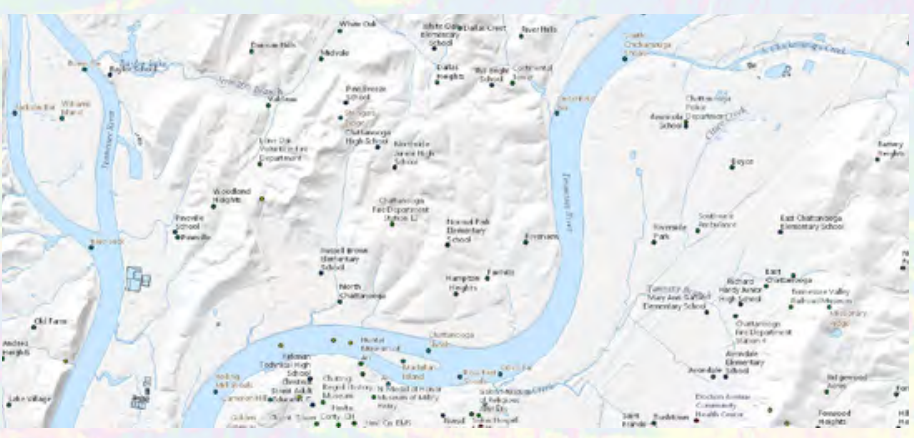

Geographic Names (GNIS) - Official U.S. geographic names service showing physical features, cities and towns, schools, police stations, cemeteries, and more.

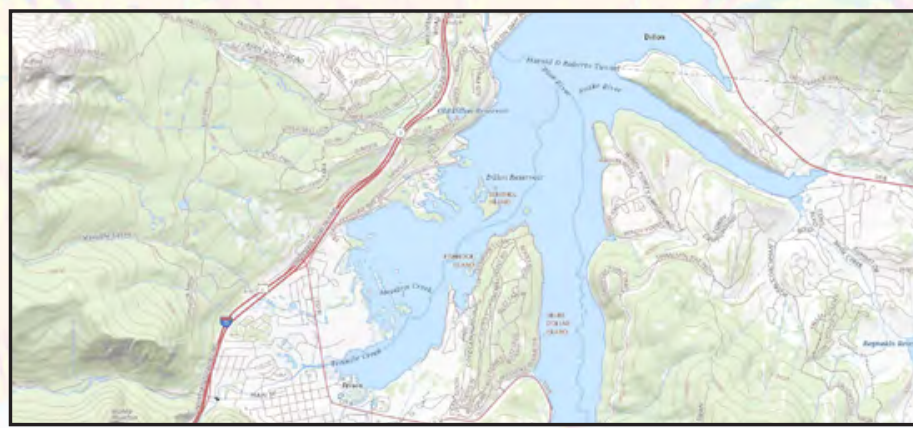

https://www.usgs.gov/NationalMap/web-services

\section{Spatial Index Services (Planned Lidar, Elevation Index, and Topo Map Index)}

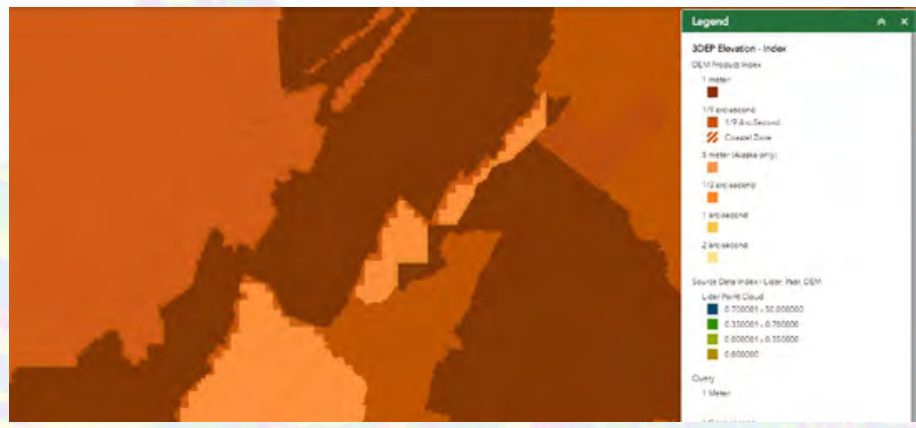

3DEP Elevation Index service shows the resolution of available elevation data.

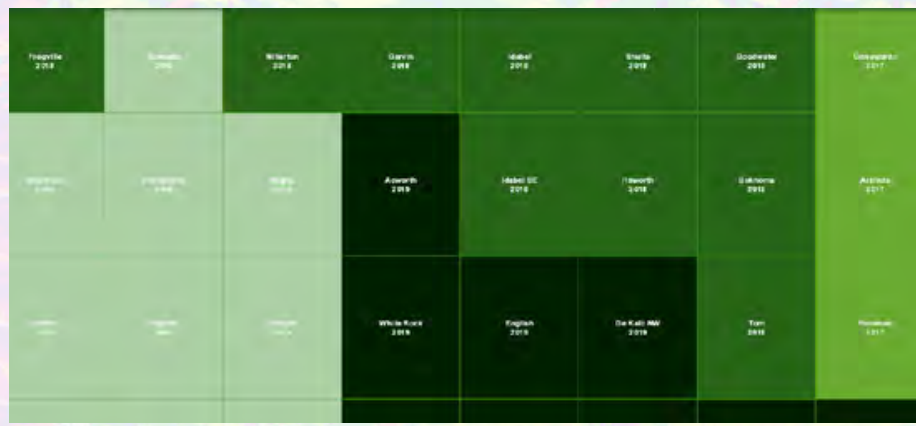

US Topo availability service shows the vintage of the most current map product.

\section{Other Developer Resources}

Application program interfaces (APIs) and Cloud Access-Most products are available from the cloud, and most of the lidar is available as Entwine Point Tiles, allowing visualization and analysis ready data access.

https://www.usgs.gov/NationalMap/apps

https://www.usgs.gov/NationalMap/data 